\title{
A PROSPECTIVE STUDY OF NASAL SYMPTOMS IN PREGNANCY
}

Soubhagini Acharya ${ }^{1}$, Bulu Nahak ${ }^{2}$

\section{HOW TO CITE THIS ARTICLE:}

Soubhagini Acharya, Bulu Nahak. "A Prospective Study of Nasal Symptoms in Pregnancy". Journal of Evolution of Medical and Dental Sciences 2015; Vol. 4, Issue 28, April 06; Page: 4897-4900,

DOI: $10.14260 /$ jemds/2015/711

ABSTRACT: INTRODUCTION: A various type of non-specific nasal symptoms like nasal obstruction, nasal discharge, bleeding occurs during pregnancy. This may due to increase in estrogen and progesterone hormone level or increase in blood volume. They are mostly physiological and some can become pathological cause considerable discomfort and anxiety. AIMS AND OBJECTIVE: To know various nasal symptoms during pregnancy and follow a definite management protocol. MATERIAL AND METHOD: A total of 2210 cases were reported in dept. of obstetrics and gynecology. Among them 242 case were referred to dept. of ENT and head and neck surgery. Proper history was taken effect of quality of life due to nasal symptoms recorded, physical exam of nose and oropharynx done. CONCLUSION: Nasal obstruction, nasal discharge, epistaxis are most common symptoms during pregnancy. In pregnancy rhinitis conservative treatment was given in the form of nasal irrigation and hypertonic saline and if topical nasal decongestants are to be prescribed then for short time only.

KEYWORDS: Pregnancy, nasal symptoms, topical decongestants.

\section{INTRODUCTION:}

- A significant number of changes occur throughout the female body during pregnancy. Although most of these physiological and hormonal processes produce no harm to the expentent mother and foetus, some can become pathological and cause considerable discomfort and anxiety.

- According to some study, nasal symptoms consists of $20-30 \%$ of pregnant female. Nasal congetion most common symptom. E Karlson ${ }^{1}$ has suggested so. Some of differential diagnosis of nasal symptoms are:

1. Allergic rhinitis.

2. Non allergic rhinitis includes idiopathic rhinitis/vasomotor rhinitis or NANIPER (Nonallergic non-infectious perennial rhinitis), non-allergic occupational rhinitis, hormonal rhinitis, drug induced rhinitis, other forms (NARES), rhinitis due to physical and chemical factors, food induced rhinitis, emotional rhinitis, atrophic rhinitis.

Conditions that mimics rhinitis like DNS.

3. Epistaxis.

4. Nasal polyps.

Hormonal rhinitis is often associated with pregnancy in particular, although is also known to induce symptoms. Incidence ranges from $10-20 \%$. Ellegard, $m$ toren ${ }^{2}$ has suggested this incidence is around 15\%. Even though the underlying cause of pregnancy has not been fully elucidated, numerous theories have been suggested.

\section{Some of the proposed theories are enlisted below:}

1. Elevated estrogens and progesterone level.

2. Increased mucosal acetylcholine receptors. 


\section{CASE REPORT}

3. Increased blood volume with extravascular engorgement and Congestion.

4. Rising level of prolactin growth hormone.

5. Elevated inflammatory response.

- Drug induced rhinitis are aspirin, NSAIDS, beta blockers, ace inhibitors, methyldopa, oral contraceptives, psychotropic agents and nasal topical agents (Oxymetazoline, naphazoline, xylometazoline) may induce symptoms of rhinitis when they are administered topically or systematically.

- NARES originally introduced by Mullarkey and colleagues, which is characterized by the condition on the basis of the presence of greater than $20 \%$ eosinophil in nasal smear of symptomatic patients.

- Epistaxis during pregnancy incidence is approximately $20 \%$.dugan $\mathrm{kim}^{3}$ has suggested that epistaxis is due to hormonal changes. It is likely caused by endocrine alteration in nasal mucosa and increased vascular congestion. Hemangiomas sometimes appear in early months of pregnancy which involutes post-partum.

\section{AIM OF THE STUDY:}

1. To know the incidence of various nasal symptoms during pregnancy.

2. To follow a definite management protocol to reduce the hospital study.

3. To review of literature.

MATERIALS AND METHODS: A prospective study was carried out over a period of one year from April 2013 to March 2014 in the OPD of department of obstetrics and gynecology. All he antenatal patients with nasal symptoms were reported. A total cases of 2210 cases were reported Out of these 242 were referred to ENT department for treatment.

History of the patient: chief concern, chronicity, seasonality and any triggering factor. Effect in the quality of life: Fatigability, sleep disturbances and attention problem. Physical examination: nasal and oropharyngeal examination.

\section{RESULTS AND OBSERVATIONS:}

- A total cases of 2210 nasal symptoms during pregnancy were reported. Out of which 242 cases were referred to ENT OPD. Cases were presented in different trimester of pregnancy.

- $\quad 1$ st trimester (1-12weeks) 46\%.

- 2nd trimester (13-28weeks) 37\%.

- 3rd trimester (29-40weeks) 17\%.

- Case 1: 22year old female with 8 months of amenorrhoea presented with epistaxsis.

- Case 2: In our one year study a 24year old female with 6 months of amenorrhoea presented with nasal polyposis with 20 day history of presentation.

Most of the cases were treated conservatively and assurance was given. Surgical intervention was carried for nasal polyposis under LA. Polypectomy was done.

Hormonal rhinitis subsided by itself after delivery. Among epistaxsis, 6 patients were given merocel. Others were managed conservatively with botroclot solute. 


\section{DISCUSSION:}

- Nasal symptoms are common during pregnancy. According to Bende m, GredmarkT, ${ }^{4}$ nasal stuffiness in pregnancy incidence in 20 weeks of gestation-27\%, 20 weeks of gestation-37\%, 30 weeks of gestation- $40 \%$ 36weeks of gestation-42\%. According to DanaWallace and Mark S. Dykewicz, The diagnosis and management of rhinitis mentioned pregnancy rhinitis is common during 2nd trimester of pregnancy.

- ENT complaints in pregnancy by TE Havas suggested that rhinitis can start during any trimester of pregnancy. In our study it is more common during 1st trimester of pregnancy.

- Epistaxis in pregnancy and associated with postpartum haemorrhage by Dugan-Kim M shows incidence of epistaxis during pregnancy is $20 \%$. In our study epistaxis we got $12 \%$ of all nasal symptoms.

- In pregnancy the nasal mucosa appears swollen and often hyperaemic. One should be careful while selecting drugs.

CONCLUSION: In pregnancy rhinitis, conservative treatment is the norm. The mainstay of treatment is nasal irrigation with hypertonic saline. Assurance should be given as most of the symptoms disappear after delivery and avoidance of unnecessary treatment can reduce risk to both mother and fetus.

In severe cases sodium cromolyn is the safe treatment for all allergic rhinitis. The most critical time for concern about potential congenital malformation because of medication used in first trimester, when organogenesis occurs. Topical decongestant when used for short time basis may have a better safety profile than oral agents for 1st trimester. Oral decongestants can cause gastroschisis and small intestine atresia.

Epistaxis is due to increased vascularity of nasal mucosa due to hormonal change. Treatment includes 30 minutes of direct local pressure. Once the bleeding stops, saline nasal sprays must be given. Severe cases must be treated accordingly

\section{REFERENCES:}

1. Ellegarde, karlson G. Nasal congestion during pregnancy. Clin otolaryngol allied sci. 1999; 307311.

2. Ellegard E, Hellgren M, Toren K, Karlson G. The incidence of pregnancy rhinitis. Gynecol Obstet Invest 2000; 49: 98-101.

3. Dugan-Kim M, Connell S, Stika C, Wong CA, Gossett DR. Epistaxis in pregnancy and association with post-partum haemorrhage.

4. Bende M, Gredmark T. Nasal stuffiness diring pregnancy. Laryngoscope. 1999july; 109: 1108-10. 


\section{AUTHORS:}

1. Soubhagini Acharya

2. Bulu Nahak

\section{PARTICULARS OF CONTRIBUTORS:}

1. Associate Professor, Department of ENT, V. S. S. Medical College \& Hospital, Burla.

2. Post Graduate, Department of ENT, V. S. S. Medical College \& Hospital, Burla.

\section{FINANCIAL OR OTHER}

COMPETING INTERESTS: None

\section{NAME ADDRESS EMAIL ID OF THE} CORRESPONDING AUTHOR:

Dr. Bulu Nahak,

H. S. Hostel, Room No. 232,

V.S. S. Medical College,

Burla, Sambarpur,

Odisha-768017.

E-mail: drbulu2004@gmail.com

Date of Submission: 06/02/2015.

Date of Peer Review: 07/02/2015.

Date of Acceptance: 08/03/2015.

Date of Publishing: 06/04/2015. 